\title{
REFLEXOS E RESULTADOS DO PNI DESDE SUA IMPLEMENTAÇÃO ATÉ O PRESENTE
}

\author{
REFLECTIONS AND RESULTS PNI FROM ITS IMPLEMENTATION TO THE PRESENT
}

Jean Carlos Lima de Sousa ${ }^{1}$, Rodrigo José Fernandes de Barros ${ }^{2}$, Jamile Rodrigues Cosme de Holanda $^{2}$, Joyce Beatriz Marinho Ferreira ${ }^{1}$, Ana Gabriella Rebouças Almeida ${ }^{1}$, Fernanda Bruna de Medeiros Freire $^{1}$, Samuel Nascimento de Brito ${ }^{1}$, Luana Lucena de Araújo ${ }^{1}$, Thiago Melo Mourão ${ }^{1}$

${ }^{1}$ Acadêmicos da Faculdade Nova Esperança de Mossoró (FACENE/RN)

${ }^{2}$ Professor da Faculdade Nova Esperança de Mossoró (FACENE/RN)

\section{Info}

Recebido: 07/2020

Publicado: $10 / 2021$

DOI: $10.37951 / 2358-260 X .2021 v 8 \mathrm{i} 2.5875$

ISSN: 2358-260X

\section{Palavras-Chave \\ Saúde coletiva, Desenvolvimento, Vacinação. \\ Keywords: \\ Collective Health, Development, Vaccination.}

\section{Resumo}

O Programa Nacional de Imunizações representa uma intervenção em saúde pública, com ações de vacinação e vigilância obtendo impacto positivo na prevenção e controle das doenças imunopreveníveis, além de melhora na qualidade e expectativa de vida da população, assim, tornando-se importante estudar seus resultados desde a implementação até a atualidade: Identificar e analisar por meio de uma revisão bibliográfica, os resultados e reflexos desde a implementação até o presente, do PNI. Foi realizada uma revisão integrativa da literatura, utilizando a base de dados Scielo, apoiada na questão norteadora "Quais os reflexos e resultados do Programa Nacional de Imunização desde sua implementação até o hodierno?". Foram utilizados para isso os descritores "Resultados", "Reflexos" e "Programas de Imunização", escritos em português e em inglês, alternados com operador booleano AND. Os critérios de inclusão foram artigos de revisão e de pesquisa completos e gratuitos no período de 20002020; e os de exclusão foram relatos de experiência, de caso. Perante os artigos e estudos analisados, o PNI desde a sua implementação como programa no Brasil, houve grandes avanços na qualidade de vida da sociedade, pois foram perceptíveis os números epidemiológicos de casos diminuindo com a aplicação das vacinas como acesso da população a mesma, portanto, devido os efeitos colossais positivos atingido pelo programa, viu-se o Brasil se tornando referência internacional em imunização. Conclui-se que o Programa Nacional de Imunizações é de extrema importância para a sociedade brasileira, pois o mesmo possui uma organização e logistica ímpar que permite desde classes abastadas a carentes o acesso a vacinas, tornando efetivos os princípios do sistema único de saúde.

\footnotetext{
Abstract

The National Immunization Program represents a public health intervention, with vaccination and surveillance actions obtaining a positive impact on the prevention and control of immunopreventable diseases, as well as improvement in the quality and life expectancy of the population, thus making it important to study its results from implementation to date. To identify and analyze through a literature review, the results and reflexes, from the implementation to the present, of the National Immunization Program. An integrative literature review was conducted, using the Scielo database, supported by the guide question "What are the reflexes and results of the National Immunization Program since its implementation to today?". The descriptors "Results","Reflexes" and "Immunization Programs" were used for this, written in Portuguese and in English, alternated with boolean operator AND. Inclusion criteria were complete and free review and research articles in the period 2000-2020; and exclusion reports were case-related experience reports. In view of the articles and studies analyzed, the PNI since its implementation as a program in Brazil, there have been great advances in the quality of life of society, because the epidemiological numbers of cases were noticeable with the application of vaccines as access of the same population, therefore, due to the positive colossal effects achieved by the program, Brazil was seen becoming an international reference in immunization. It is concluded that the National Immunization Program is extremely important for Brazilian society, because it has a unique organization and logistics that allows from wealthy classes to needy access to vaccines, making effective the principles of the unified health system.
} 


\section{INTRODUÇÃO}

O presente artigo tem por escopo sistematizar os reflexos e resultados do PNI desde sua implementação até os dias atuais. O PNI representa uma das mais importantes intervenções de saúde pública na situação de saúde do Brasil. As ações de vacinação e vigilância têm impacto positivo na prevenção e controle das doenças imunopreveníveis, além de impacto positivo e direto na qualidade e expectativa de vida da população. Vale ressaltar que o sucesso da operação de imunização está atrelado a diversos fatores dos órgãos gestores competentes, tais como compra, planejamento, infraestrutura, logística, treinamento e recursos humanos, fatores estes assegurados nas diversas operações.

Toda população brasileira tem acesso gratuito a todas as vacinas recomendadas pela Organização Mundial de Saúde (OMS). Desde a sua criação em 1973, o programa aposta na integração social, prestando assistência a todas as pessoas em todo o país sem distinção. As vacinas do plano estão à disposição no posto de saúde ou com as equipes de vacinação, e seus esforços permitem imunizar mesmo em locais de difícil acesso.

O Programa Nacional de Imunizações (PNI) é encarregado de ser o órgão de política nacional de imunizações e promove ações integradas de vigilância em saúde para promoção, proteção e prevenção em saúde da população brasileira visando reduzir a morbimortalidade por doenças imunopreveníveis.

Para elaboração deste artigo, utilizamos uma revisão integrativa da literatura com os descritores: "Resultados", "Reflexos" e "Programas de Imunização", cuja principal fonte de pesquisa bibliográfica foram trabalhos indexados nas bases de dados SCIELO e PUBMED, dos últimos 20 anos (2000 a 2020), bem como livros-texto e periódicos, conforme referências anexadas. $\mathrm{O}$ presente trabalho apoiou-se na questão norteadora "Quais os reflexos e resultados do Programa Nacional de Imunização desde sua implementação até o hodierno?"

Desta forma, foram relatados fatos históricos a partir dos anos 1.500, que desencadearam no progressivo desenvolvimento do PNI, nos permitindo identificar os problemas de saúde pública antes do advento dos diversos imunizantes atualmente disponibilizados, e os impactos positivos com a implementação do PNI para população brasileira, que acrescido a este período, eventos históricos e marcantes no estabelecimento e desenvolvimentos de imunizantes. Ao todo foram utilizados 3 artigos, os quais encontram-se identificados por título, autores e ano de publicação, nos quais os critérios de inclusão foram artigos de revisão e de pesquisa completos e gratuitos no período de 2000-2020; e os de exclusão foram relatos de experiência, de caso, escritos em português e em inglês.

\section{REVISÃO DA LITERATURA}

\section{Principais marcos históricos nacionais e internacionais}

A priori, quando se trata de fatos e datas históricas das imunizações, a data de 1563, foi marcada pelo registro do início da primeira epidemia da enfermidade conhecida como Varíola. Anos depois, em 1789, na Inglaterra, Michael Underwood descreve pela primeira vez as fragilidades de uma criança diagnosticada com poliomielite. Após sete anos, em 1796, a primeira vacina é descoberta e o procedimento da vacinação consistiu em inocular, nos indivíduos, um material logrado a partir de lesões, causadas por essa doença, em vacas, conferindo, assim, imunidade aos seres humanos, sendo disseminada pelo mundo a partir de 1805.

No Brasil, a vacinação contra a varíola foi introduzida pelo Marquês de Barbacena, que trazia nos 
braços dos escravos, advindo de Portugal, o vírus vacínico, espalhando por todo o país, sendo o procedimento realizado a partir da colheita da linfa dos escravos, introduzindo em outra pessoa, imunizando-a. Porém, essa vacina só começou a ser produzida, em laboratório no Brasil, a partir de 1887, por intermédio do então diretor da Santa Casa de Misericórdia de São Paulo, Barão Pedro Afonso.

Outro marco histórico foi o surto de peste bubônica, propagado em 1889, no porto de Santos, o que levou o governo a instalar um laboratório para produção de soros antipestoso, já que a vacina contra tal patologia só foi introduzida a partir de 1897. No início do século XX, surge, então, a epidemia de febre amarela, que aumentou as taxas de mortalidade da época, constituindo um grave problema de Saúde Pública, cuja vacina só foi descoberta em 1935. No ano de 1903, deflagrou-se, no Rio de Janeiro, epidemias de peste bubônica e varíola, além da já citada. A partir disso, faz-se necessário citar a figura de Oswaldo Cruz, que criou o movimento sanitarista e a campanha de vacinação obrigatória, em 1904, resultando em um movimento popular, conhecido como Revolta da Vacina. Não obstante, os números de mortes pela varíola, após as campanhas citadas, decaem, até que uma nova epidemia de varíola faz a população, por conta própria, procurar os postos de vacinação.

Em 1919, a primeira criança, no mundo, recebeu uma dose, via oral, de BCG, vacina desenvolvida na França, em 1906, a partir de cepas da bactéria denominada Mycobacterium bovis. Após alguns anos de descobertas em todo o mundo e amenização da incidência de algumas doenças, graças às introduções de vacinas na população, no início dos anos 50 há a introdução do toxóide tetânico e da vacina Tríplice Bacteriana (DTP), em alguns estados do Brasil, por meio de programas isolados. No ano de
1961, no Brasil, há o início das primeiras campanhas de vacinação, por via oral, contra a poliomielite e em 1962 tem-se a primeira campanha de imunização nacional contra a varíola. Então, até o final dos anos 60, são disseminadas pelo Brasil, as vacinas, principalmente, contra o sarampo, a caxumba e rubéola. A partir do início dos anos 70 uma série de programas de erradicação e intensificação da vacinação em todo o Brasil foram executadas, até chegar ao marco de 1972 com a implantação do Programa Nacional de Imunização (PNI).

\section{Estruturação do Plano Nacional de Imunizações (PNI)}

O PNI, nascido em 18 de setembro de 1973, chega aos 30 anos mostrando resultados e avanços notáveis. Fato este reconhecido pela Organização PanAmericana da Saúde (OPAS), que é braço da Organização Mundial de Saúde (OMS), no qual o PNI brasileiro é citado como referência mundial. O documento com a proposta básica do PNI foi elaborado por técnicos do Departamento Nacional de Profilaxia e Controle de Doenças (Ministério da Saúde) e da Central de Medicamentos (Ceme Presidência da República). Esse documento foi aprovado em 18 de setembro de 1973, considerada a data de nascimento do PNI.

As competências do Programa, estabelecidas no Decreto no 78.231, de 12 de agosto de 1976 (o mesmo que o institucionalizou), são ainda válidas até hoje:

- Implantar e implementar as ações relacionadas com as vacinações de caráter obrigatório;

- Estabelecer critérios e prestar apoio técnico à elaboração, implantação e implementação dos programas de vacinação a cargo das secretarias de saúde das unidades federadas; 
- Estabelecer normas básicas para a execução das vacinações;

- Supervisionar, controlar e avaliar a execução das vacinações no território nacional, principalmente o desempenho dos órgãos das secretarias de saúde, encarregados dos programas de vacinação;

- Centralizar, analisar e divulgar as informações referentes ao PNI.

As competências do Programa, estabelecidas no Decreto n ${ }^{\circ}$ 78.231, de 12 de agosto de 1976 (o mesmo que o institucionalizou), são válidas até hoje:

- Implantar e implementar as ações relacionadas com as vacinações de caráter obrigatório;

- Estabelecer critérios e prestar apoio técnico à elaboração, implantação e implementação dos programas de vacinação a cargo das secretarias de saúde das unidades federadas;

- Estabelecer normas básicas para a execução das vacinações;

- Supervisionar, controlar e avaliar a execução das vacinações no território nacional, principalmente o desempenho dos órgãos das secretarias de saúde, encarregados dos programas de vacinação;

- Centralizar, analisar e divulgar as informações referentes ao pni.

A institucionalização do Programa se deu sob influência de vários fatores nacionais e internacionais, entre os quais se destacam os seguintes:

- Fim da Campanha da Erradicação da Varíola (CEV) no Brasil, com a certificação de desaparecimento da doença por comissão da OMS;
- A atuação da Ceme, criada em 1971, voltada para a organização dum sistema de produção nacional e suprimentos de medicamentos essenciais à rede de serviços públicos de saúde;

- Recomendações do Plano Decenal de Saúde para as Américas, aprovado na III Reunião de Ministros da Saúde (Chile, 1972), com ênfase na necessidade de coordenar esforços para controlar, no continente, as doenças evitáveis por imunização.

\section{Reflexos epidemiológicos após a implantação da PNI.}

Uma breve noção do impacto da PNI no Brasil, foi a história da luta contra o sarampo que teve um final feliz. Antes do PNI, em 1970, o registro oficial do Ministério da Saúde foi de 109.125 casos, em que houve epidemias em 1980, 1984, 1986 e 1990. Em 1992, foi iniciado o Plano de Controle e Eliminação do Sarampo, assim foi implementada também a vigilância epidemiológica da doença em todo o País. A Campanha Nacional de Vacinação contra o Sarampo foi realizada entre 25 de abril e 22 de maio, com a vacinação de mais de 48 milhões de crianças entre 9 meses e 14 anos de idade, ou 96\% da população que se pretendia atingir. Um êxito nunca obtido em país com as dimensões continentais do Brasil. Os números mostram que o Plano funcionou:

- $\quad 45.778$ casos registrados em 1990.

- $\quad 23.990$ casos registrados em 1991.

- $\quad 3.234$ casos registrados em 1992.

Após a implantação do Plano, houve pequenos surtos em 1992, 1993 e 1994, com mais de 50\% dos casos entre maiores de 15 anos. Em 1995 não houve registros de surtos. Em 1996 foram identificados três casos (importados de outros países) e surtos em dois estados. Em 1997, o número de casos 
cresceu em São Paulo, com exportação para outros estados e rápida expansão da doença. Hoje, pode-se afirmar que o sarampo é uma doença em processo de erradicação no Brasil, mas estratégias vêm sendo implementadas em vigilância e imunizações, visando a manutenção da situação epidemiológica do Brasil, pois devido sua magnitude econômica, turística e espacial com fluxos constantes de pessoas internacionais entrando e saindo do país, em imperativo manter-se essa manutenção e prevenção no país.

Assim, percebe-se que desde as primeiras vacinações, em 1804, até a atualidade, o Brasil acumulou quase 200 anos de imunizações — sendo que nos últimos 30 anos, com a criação do PNI, desenvolveu ações planejadas, sistematizadas e organizativas como proposta para o avanço das imunizações como nunca visto na história do Brasil.

O Brasil precisou alcançar resultados vantajosos e satisfatórios no espectro de sua ação imunizaria, e para isso investiu-se vultosos recursos na adequação de sua Rede de Frio, na vigilância de eventos adversos pós-vacinais, na universalidade de atendimento, nos seus sistemas de informação, descentralizou as ações e garantiu capacitação e atualização técnico-gerencial para seus gestores em todos os âmbitos durante a história do Brasil, não é à toa que de 1997 para cá, multiplicou-se em quase cinco vezes o orçamento do Ministério para a aquisição de vacinas. Com isso, as campanhas nacionais de vacinação, voltadas em cada ocasião para diferentes faixas etárias, proporcionaram o crescimento da conscientização social a respeito da cultura em saúde.

Dessa forma, o aperfeiçoamento do PNI, nesses 30 anos, tem um ponto especialmente importante na descentralização de suas ações, visto que, anteriormente era centralizado. Atualmente, o Programa apresenta um novo perfil gerencial, com integração entre os três níveis - municipal, estadual e federal —, que, juntos, discutem normas, definições, metas e resultados, propiciando a modernização contínua de sua infraestrutura e operacionalização. Portanto, o grande executor das ações é o município, os estados coordenam, assessoram tecnicamente, e o Ministério da Saúde mantém ações essenciais, como o fornecimento das vacinas.

Porém, mesmo diante dessa organização, sabe-se que a vacinação no Brasil associado a logística e é obviamente dificultada, um reflexo ainda contínuo hodiernamente, pois sabemos que por mais que o programa atuante e representante do SUS leve profissionais qualificados até sua residência, tem-se dificuldades no trânsito desde a produção da vacina até a aplicação no paciente. Em exemplo, cita-se favelas, com seus becos, vielas, labirintos, barram a passagem das vacinadoras, dificultam o acesso dos moradores aos postos de vacinação, tentando manter a homogeneidade da cobertura de vacinação.

\section{Investimentos no desenvolvimento de tecnologias e produção de imunizantes}

O PNI mantém uma política de parcerias e de incentivo à modernização tecnológica do parque produtor nacional, visando oferecer produtos que acompanhem o que há de mais novo, seguro e eficaz no mercado internacional. Assim, esse programa é totalmente custeado com dinheiro público, aceitando assessoria técnica de parceiros internacionais e da iniciativa privada, porém, acredita que as ações continuadas, como a vacinação, devem ser custeadas com recursos do Governo.

Antes, no Brasil, as ações de imunização se voltavam ao controle de doenças específicas. Com o PNI, passou a existir uma atuação ampla e de rotina: objetiva-se estar atento à erradicação e ao controle de doenças que sejam possíveis de controlar e erradicar 
por meio dos imunizantes. O objetivo prioritário do PNI, ao nascer, era promover o controle da poliomielite, do sarampo, da tuberculose, da difteria, do tétano, da coqueluche e manter erradicada a varíola. Hoje, o PNI tem um objetivo mais amplo, conforme as metas citadas a seguir:

- Ampliação da auto-suficiência nacional dos produtos adquiridos e utilizados pela população brasileira;

- Produção da vacina contra haemophilus influenzae b, da vacina combinada tetravalente (dtp + hib), da dupla viral (contra sarampo e rubéola) e tríplice viral (contra sarampo, rubéola e caxumba), da vacina contra pneumococos e da vacina contra influenza e da vacina anti-rábica em cultivo celular.

Em 2003, o Programa organizou e implementou um conjunto de medidas voltadas aos estados e municípios, em meio a outras preocupações, tais como os processos de aperfeiçoamento do modelo e dos instrumentos de gestão, especialmente no que se refere à redução de perdas de vacinas e à otimização das operações de distribuição e armazenagem de vacinas e demais insumos.

No histórico do PNI, duas providências foram especialmente importantes: a implantação dos Centros de Referência para Imunobiológicos Especiais (Cries), desde 1993, e a criação, em 1991, do Comitê Técnico Assessor em Imunizações (CTAI). Os Cries são unidades de vacinação públicas e gratuitas que oferecem produtos especiais a indivíduos que necessitam de imunobiológicos específicos, mediante prescrição médica.

Hoje, os Cries contam com um sistema informatizado para o controle e avaliação de suas ações, o SI-Crie. Beneficiam-se dos Cries pacientes que podem ser agrupados em três principais categorias:

- Profilaxia pré e pós-exposição a agentes infecciosos em determinados grupos de risco

- Substituição de produtos disponíveis na rede básica do país, quando não puderem ser utilizados devido a motivos clínicos

- Imunização de imunodeficientes.

O CTAI é composto por membros nomeados pelo Ministro da Saúde, profissionais experts em áreas afins, representantes de sociedades médicas das cinco macrorregiões do País, do Instituto Nacional de Controle de Qualidade em Saúde/Fundação Oswaldo Cruz (INCQS/Fiocruz), da Vigilância Epidemiológica Nacional e do PNI. Com caráter consultivo, o Comitê tem por finalidade assessorar o Ministério da Saúde na identificação de prioridades, na formulação de diretrizes nacionais nas áreas de pesquisa, produção, aquisição, distribuição e utilização de imunobiológicos, fundamentado em avaliações sistemáticas e em dados técnico-científicos atualizados.

O PNI é um programa para toda a população, não somente para crianças, em que procura-se colocar em constante atualização, em que se observa o aumento gradativo da expectativa de vida, visando a construção de medidas quantitativas e qualitativas devido essa mudança da pirâmide etária no Brasil. Além disso, existe a preocupação de valorizar os integrantes do PNI, usar a sua experiência, mas ainda persistem alguns elementos de perturbação, como o fato de o vacinador ser remunerado de acordo com o vínculo contratual que têm: municipal, estadual, federal.

O Programa tem recebidos expressivos e crescentes investimentos em seu orçamento, isso com o fito de ampliar a produção nacional e evitar a possível falta de vacinas preconizadas e estabelecidas. Desde 1996 ampliou-se o apoio à produção nacional, 
de modo a evitar a falta de vacinas preconizadas. Atualmente, a CGPNI compõe a recém-criada Secretaria de Vigilância em Saúde (SVS), do Ministério da Saúde.

\section{Gestão descentralizada e êxito na implementação} das ações de imunização

O PNI é um programa enorme, com um único calendário no Brasil inteiro, com seus 23 mil postos de vacinação, em que desde 1992 o Brasil tem conseguido resultados muito bons, com uma cobertura vacinal adequada, até como efeito do processo de descentralização. O detalhe de as esferas governamentais procurar a responsabilidade de vacinar sua população, fez com que traçassem metas e buscando soluções para atingir populações carentes, como executar a vacinação em regiões de difícil acesso ou garantir o acesso da população mais carente ao programa.

O Programa conquistou, ao longo desses anos, grande respaldo perante a comunidade médica brasileira. Sociedades de especialistas, como a Sociedade Brasileira de Pediatria, a Federação Brasileira das Sociedades de Ginecologia e Obstetrícia e a Sociedade Brasileira de Medicina Tropical, convidam representantes do PNI para participarem de mesas-redondas e conferências, porque sabem que eles têm o que dizer. Sabem que esses profissionais argumentaram com base em evidências técnicas e científicas.

buscassem agir de forma efetiva com suas ações,

\begin{tabular}{|c|c|c|}
\hline Vacinas & Paises em Desenvolvimento & Paises Industrializados \\
\hline Sarampo & Sarampo & MMR (sarampo, caxumba, rubéola) \\
\hline DTP & DTwP* & $\mathrm{DTaP}^{\star \star}$ \\
\hline Poliomielite & OPV & IPV \\
\hline \multirow[t]{6}{*}{ Hep B } & Monovalente & Monovalente \\
\hline & DTwP+Hep B & DTa P-Hep B \\
\hline & & DTaP-Hep \\
\hline & & B-IPV-Hib \\
\hline & & Hep B-Hib \\
\hline & & Hep A-Hep B \\
\hline \multirow[t]{3}{*}{$\mathrm{Hib}$} & Monovalente & Monovalente \\
\hline & DTwP-Hib & DTaP-Hep B-IPV-Hib \\
\hline & DTwP-Hep B-Hib & Hep B-Hib \\
\hline Meningitis AVC Polissacarídeo & Meningite $A / C$ conjugada (requerida) & $\begin{array}{l}\text { Meningite } C \text { conjugada } \\
\text { (Meningite } B / C \text { conjugada) }\end{array}$ \\
\hline \multirow[t]{2}{*}{ Pneumococos Polissacarídeo } & 11 -valente conjugada (requerida) & 7-valente conjugada \\
\hline & & 11-valente conjugada (em desenvolvimento) \\
\hline \multirow[t]{2}{*}{ Apresentação } & Multidose & Monodose \\
\hline & Com timerosal & Sem timerosal \\
\hline
\end{tabular}

Figura 1: Demonstrativo de Programas de Imunizações em diversos países do mundo.

O primeiro grande êxito do PNI foi o de implementar amplas ações nacionais de vacinação. $\mathrm{O}$ segundo é que ficou garantida, ao longo desse tempo, a incorporação de novas vacinas. O calendário brasileiro de vacinação, com oferta gratuita para toda a população, é um dos mais completos do mundo. Existem, sim, vacinas no sistema de saúde privado, mas quase todas estão incorporadas ao sistema público de vacinação, como a vacina contra gripe para idoso e a vacina contra a rubéola. O PNI deixou de ser só um 
programa de vacinação para crianças, para ser um programa mais amplo, para toda a população.

\section{CONSIDERAÇÕES FINAIS}

As medidas relacionadas à vacinação são as de melhores custo-benefício formuladas pelo Ministério da Saúde, caracterizada pela inclusão social, na medida em que assiste a todas as classes sociais, sem distinção de qualquer natureza, gratuitamente. Nas últimas décadas, a morbimortalidade vem diminuindo no Brasil e no mundo devido às doenças evitáveis, especialmente a redução da mortalidade infantil e o aumento da expectativa de vida, o que mostra que as vacinas têm proporcionado enormes benefícios à população. Por meio da vacinação, doenças globais como varíola e poliomielite foram erradicadas.

O PNI, tem cumprido o seu objetivo com enorme desenvolvimento, desenvolvimento este associado a normas técnicas rígidas como conservação, transporte, manipulação e entre outros, cumprindo, portanto, com suas orientações e objetivos. É válido lembrar que a qualidade dos produtos distribuídos é garantida pelo Instituto Nacional de Controle de Qualidade em Saúde (INCQS), criado desde 1981, órgão referência para laboratórios técnicos produtores, as amostras de todos os lotes são analisadas antes da distribuição para consumo.

Quanto aos dados epidemiológicos, conclui-se que o PNI está em constante desenvolvimento e modernização tecnológica, na medida do possível, contando com vacinas consideradas especiais para grupos em condições clínicas diferenciadas, como por exemplo os portadores de HIV. Vale destacar também a implementação das Cries nas quais oferecem produtos especiais a indivíduos que necessitam de imunobiológicos específicos. E o CTAI com caráter consultivo sobre aspectos técnicos e científicos necessários à proposição da Política Nacional de Imunizações.

Conforme demonstrado ao longo do presente trabalho, conclui-se que o Programa Nacional de Imunizações é de extrema importância para a sociedade brasileira, pois o mesmo possui uma organização e logística ímpar, que permite o acesso aos imunizantes desde classes abastadas até às mais carentes, tornando efetivos os princípios do Sistema Único de Saúde (SUS).

Perante os artigos e estudos analisados, o PNI desde a sua implementação como programa no Brasil, houve grandes avanços na qualidade de vida da sociedade, pois foram perceptíveis os números epidemiológicos de casos diminuindo com a aplicação das vacinas, como o acesso da população às mesmas. Portanto, devido aos colossais efeitos positivos atingidos pelo programa, viu-se o Brasil se tornando referência internacional em imunização.

\section{REFERÊNCIAS BIBLIOGRÁFICAS}

BRASIL. Ministério da Saúde. Campanha Programa Nacional de Imunizações: Aplicativo Vacinação em Dia. Brasília: Ministério da Saúde, 2021. Disponível em:

$<$ https://portalarquivos.saude.gov.br/campanh as/pni/>. Acesso em 16 maio 2021.

- Ministério da Saúde. Meu digiSUS. Brasília: Ministério da Saúde, 2021. Disponível em: < https://datasus.saude.gov.br/meudigisus-2/>. Acesso em 16 maio 2021.

- Ministério da Saúde. Secretaria de Vigilância em Saúde. Programa Nacional de Imunizações 30 anos. Brasília: Ministério da Saúde, 2003. Disponível em: https://bvsms.saude.gov.br/bvs/publicacoes/li vro_30_anos_pni.pdf. Acesso em 16 maio 2021.

Fonte: Milstei, J. 2001.Célula inteira do componente Pertussis. ${ }^{*}$ Componente Pertussis acelular. 
DOMINGUES, Carla Magda Allan Santos; MARANHÃO, Ana Goretti K.; TEIXEIRA, Antonia Maria; FANTINATO, Francieli F. S.; DOMINGUES, Raissa A. S.. 46 anos do Programa Nacional de Imunizações: uma história repleta de conquistas e desafios a serem superados. Cadernos de Saúde Pública, [S.L.], v. 36, n. 2, p. 1-17, abr. 2020. FapUNIFESP (SciELO). http://dx.doi.org/10.1590/0102311x00222919.

DOMINGUES, Carla Magda Allan Santos; FANTINATO, Francielli Fontana Sutile Tardetti; DUARTE, Elisete; GARCIA, Leila Posenato. Vacina Brasil e estratégias de formação e desenvolvimento em imunizações. Epidemiologia e Serviços de Saúde, [S.L.], v.
28, n. 2, p. 1-3, nov. 2019. FapUNIFESP

(SciELO). http://dx.doi.org/10.5123/s167949742019000200024..

SATO, Ana Paula Sayuri. National Immunization Program: computerized system as a tool for new challenges. Revista de Saúde Pública, [S.L.], v. 49, n. 91, p. 1-5, jan. 2015. FapUNIFESP (SciELO).

http://dx.doi.org/10.1590/s00348910.2015049005925 .

TEMPORÃO, J.G. Complexo industrial da saúde: público e privado na produção e consumo de vacinas no Brasil. IMS/UERJ. Rio de Janeiro/RJ, 2002. (Tese de doutorado). 